\title{
Diskussion
}

\section{Die Kehrseite der Medaille}

Der folgende Beitrag ist die überarbeitete Fassung eines Vortrags, der im Rahmen der Vorlesung von Jürgen Habermas über Demokratietheorien im Sommersemester 1988 in Frankfurt/M. gehalten wurde.

Habermas rekonstruierte die Staatstheorien von Aristoteles, Locke, Rousseau und Kant unter systematischem Interesse, wobei es ihm darum ging, aus deren politischer Philosophie normative Gehalte herauszuschălen, die für eine zeitgenठssische Demokratietheorie fruchtbar gemacht werden konnen. Daß bei den genannten Theoretikern die Grundidee der »Herrschaft Freier und Gleicher über Freie und Gleiche« sowohl die Annahme "Ungleicher" als auch ihr Beherrschtwerden durch »Gleiche implizierte, wertete Habermas als »historische Blindheit« der Autoren, die angesichts der heutigen Ausdehnung des Gleichheitsbegriffs auf alle zu vernachlăssigen sei.

Der Vortrag hat hingegen die These verteidigt, daß der Ausschluß einer Gruppe „Ungleicher«, nămlich der Frauen, wesentlicher Bestandteil dieser politischen Philosophie war, und versucht dies am Beispiel Aristoteles, Rousseaus und Kants zu belegen.

Der Anspruch des Vortrags konnte nicht sein, den Gegenstand der Untersuchung er- schøpfend zu behandeln, sondern er soll die Schwăche einer Position aufzeigen, die einen systematischen Zugriff auf die Geschichte der Demokratietheorien beansprucht, dabei aber den systematischen Ausschluß von Frauen nicht zu erklären vermag.

Gabriele Neuhăuser

\section{Elisabeth Conradi}

\section{Ist der Ausschluß von Frauen für die traditionel- len Demokratietheorien grundlegend und wie wird er gerechtfertigt? ${ }^{1}$}

Enthalten die traditionellen Staatstheorien von Aristoteles, Rousseau und Kant im Ansatz ausschließende Elemente, oder ist der Ausschluß von Frauen, Sklaven, Besitzlosen, Leibeigenen und anderen Menschen als etwas bloß akzidentelles zu interpretieren, das sich wegdenken laßt aus den verschiedenen Theorien, so daß es moglich ist, eine universalistische Grundidee herauszuschalen, die dieses ausschließende Moment nicht mehr enthalt?

Ich mochte bestreiten, daß der Ausschluß lediglich auf das kontingente Phanomen »historischer Blindheit « - also auf un- 